\title{
СИСТЕМА МЕР ПРЕСЕЧЕНИЯ В РОССИЙСКОМ УГОЛОВНОМ СУДОПРОИЗВОДСТВЕ
}

\section{THE SYSTEM OF PREVENTIVE MEASURES IN THE RUSSIAN CRIMINAL PROCEEDINGS}

V. Firsov

Summary. The article analyzes the system of preventive measures in the Russian criminal proceedings to determine its criminal procedural nature and substance. At the same time, essential features are highlighted: the purpose, grounds, bases of application, subjects and objects of application, the order of application and the essence of the measures themselves, that is, what they are. In addition, the article analyzes the grounds and conditions for the selection of preventive measures, presents various classifications of measures and gives an author's definition of preventive measures.

Keywords: coercive measures; preventive measure; purpose of use; suspect; accused; grounds and conditions.
Фирсов Владимир Григорьевич

Независимый исследователь firsov_vg65@mail.ru

Аннотация. В статье проведен анализ системы мер пресечения в российском уголовном судопроизводстве для выяснения его уголовно-процессуальной природы и существа. При этом выделены существенные признаки: цель, основания, основания применения, субъекты и объекты применения, порядок применения и существо самих мер, то есть в чем они заключаются. Кроме того, в статье проанализированы основания и условия избрания мер пресечения, представлены различные классификации мер и дано авторское определение мер пресечения.

Ключевые слова: меры принуждения; меры пресечения; цели применения; подозреваемый; обвиняемый; основания и условия.

шения задач и достижения назначения уголовного процесса.

дения составляет часть правового механизма, используемого для надлежащего расследования и разрешения уголовного дела, обеспечения государственной и общественной безопасности Российской Федерации. Меры уголовно-процессуального принуждения позволяют реализовать функции уголовного преследования и разрешения уголовного дела по существу. Так, задержание подозреваемого и применение меры пресечения призваны обеспечить функции уголовного преследования, разрешения дела, а также гражданско-правовую функцию.

Практически любая из форм уголовно-процессуального принуждения всегда влечет за собой то или иное ограничение свободы граждан (свободы воли, передвижения, неприкосновенности и т.д.)[1].

Достижение необходимого правового результата в уголовно-процессуальном опосредовании общественных отношений требует и обеспечения их правовым принуждением. Способы такого обеспечения правового принуждения, признаваемые в качестве элемента метода уголовно-правового регулирования, характеризуют одну из основных черт метода воздействия уголовно-процессуального права на общественные отношения[2]. Однако принуждение в уголовном процессе не является самоцелью, это лишь способ ре-

Уголовно-процессуальное принуждение - обязательная часть уголовно-процессуального регулирования. Мерами уголовно-процессуального принуждения обеспечивается реализация норм права в случаях, когда обязанное лицо не выполняет или предположительно может не выполнить установленные законом процессуальные обязанности.

Уголовно-процессуальное законодательство Российской Федерации предусматривает возможность применения к гражданину, являющемуся подозреваемым или обвиняемым мер уголовно-процессуального принуждения, самыми строгими из которых являются меры пресечения.

Меры пресечения являются частью правового механизма, который используется правоохранительной системой для противодействия преступности и обеспечения государственной и общественной безопасности Российской Федерации. При этом, для защиты прав человека от необоснованного обвинения и осуждения государство посредством уголовно-процессуального законодательства регламентирует основания, условия и порядок применения уголовно-процессуального принуждения, устанавливает его пределы на основе обще- 
признанных принципов и норм международного права, конституционных принципов, касающихся прав и свобод человека и гражданина[3].

Цели мер пресечения взаимосвязаны с назначением уголовного судопроизводства, без мер процессуального принуждения невозможно осуществление функций уголовного преследования, разрешения уголовного дела, а также гражданско-правовой функции.

Меры пресечения являются инструментами решения превентивных, обеспечительных задач для успешного расследования и судебного разбирательства уголовного дела. Отдельные исследователи института мер процессуального принуждения считают, что «меры пресечения, являясь по сути превентивно-обеспечительными мерами, в отдельных случаях могут приобретать форму уголовно-процессуальной ответственности» [4]. Представители данной точки зрения исходят из того, что основанием уголовной ответственности в соответствии со ст. 8 УК РФ, является совершение деяния, содержащего все признаки состава преступления, предусмотренного уголовным законом.

Меры пресечения имеют отличные от наказания цели, поэтому они не могут приобретать форму уголовно-процессуальной ответственности и быть наказанием, а являются лишь правовым механизмом обеспечения привлечения к уголовной ответственности.

УПК РФ не содержит ни нормативного определения мер пресечения, ни исчерпывающего перечня целей их применения. В нем регулируются только основания применения мер пресечения.

В теории дано множество определений мер пресечения, отличающихся между собой по количеству существенных признаков и специфических характеристик.

Так, И.Л. Петрухин считает, что меры пресечения это способы принудительного воздействия на обвиняемого, а в исключительных случаях и на подозреваемого, с тем, чтобы не допустить такого их поведения, которое препятствовало бы достижению задач уголовного судопроизводства[5].

По мнению П. М. Давыдова, меры пресечения - принудительные меры, применяемые органами расследования, прокуратуры и суда в порядке, установленном уголовно-процессуальным правом, к подозреваемым, обвиняемым, подсудимым или осужденным в целях предупреждения уклонения их от следствия и суда и от отбытия наказания, а также устранения препятствий раскрытию истины и общественной опасности нахождения этих лиц на свободе[6].
Исходя из приведенных взглядов на понимание мер пресечения можно выделить следующие свойственные им существенные признаки: цель, основания применения, субъекты и объекты применения, порядок применения и существо самих мер, то есть в чем они заключаются.

Цель - это то, к чему стремятся, что нужно осуществить[7], предполагаемые результаты, на достижение которых направлены действия. Выполнение поставленной цели достигается путем постановки и решения задач.

Определение целей мер пресечения, имеет большое значение, так как позволяет ответить на вопросы, для чего эти меры пресечения применяются, на что направлены и каким образом достигаются.

В юридической теории ученые по-разному определяют цель мер пресечения. Одни авторы считают, что целью мер пресечения является «обеспечение успешности расследования и разрешения уголовного дела» [8]. По мнению других, меры пресечения применяются в целях предупреждения уклонения подозреваемых, обвиняемых, подсудимых или осужденных от следствия или суда и отбывания наказания, а также для устранения препятствий раскрытию истины и общественной опасности нахождения этих лиц на свободе[9].

Многие процессуалисты отождествляют цель применения мер пресечения и основания их применения, указанные в ст. 97 УПК РФ[10]. Данную точку зрения разделяет, например, Г.П.Ивлев, утверждавший, что только при установлении оснований законодатель называет эти обстоятельства целями. Они выступают целями во всех случаях, так как цель и есть то, что надо осуществить[11]. Аналогичной позиции придерживался и И.Л. Петрухин, который полагает, что цели могут быть представлены и как подлежащие доказыванию обстоятельства, являющиеся основанием для избрания меры пресечения[5].

Меры пресечения имеют превентивную цель: они должны предупредить возможность обвиняемого, подозреваемого скрыться от следствия и суда, а также воспрепятствовать установлению истины по делу и совершение им новых преступлений.

Таким образом, целью применения мер пресечения является содействие обеспечению уголовного преследования и назначению виновным справедливого наказания, а также защите прав и законных интересов лиц и организаций, потерпевших от преступлений, то есть выполнение назначения уголовного судопроизводства путем реализации уголовно-процессуальных функций: 
функции уголовного преследования и разрешения уголовного дела.

Общая цель мер пресечения - обеспечение решения задач уголовного судопроизводства, а соответственно и деятельности правоохранительных органов по обеспечению государственной и общественной безопасности Российской Федерации, включает в себя ряд частных целей. К ним следует отнести: предупреждение возможности обвиняемого, подозреваемого скрыться от следствия и суда, а также воспрепятствовать установлению истины по делу и совершение им новых преступлений, то есть обеспечить нормальное производство по делу и исполнение приговора, в том числе участие в судопроизводстве обвиняемого, подозреваемого, обеспечить воспитательное, предупредительное воздействие на подозреваемого, обвиняемого.

Следует согласиться с мнением 3.Д. Еникеева в части того, что система мер пресечения является совокупностью конкретных правовых средств, различающихся между собой содержанием принуждения, степенью строгости, действенностью, условиями применения и образуют иерархическую систему по степени принудительности[12].

В связи с этим нельзя поддержать точку зрения Н.В. Ткачевой, полагающей, что «список мер пресечения, закрепленный законом, не имеет систематизации. Вступивший в силу 1 июля 2002 г. УПК РФ, подобно предыдущим УПК, не говорит о перечне мер пресечения как о системе. То, что меры пресечения названы в законе в определенной последовательности, еще не свидетельствует о большей строгости одних мер пресечения по отношению к другим» [13].

Уже сам закрепленный в законе порядок расположения мер пресечения (глава 13 УПК РФ) свидетельствует о системном порядке их закрепления, имеющем в качестве основания строгость меры пресечения.

Система мер пресечения имеет закономерно расположенные части, находящиеся во взаимной связи, характеризующиеся: наличием общих и специальных оснований и условий избрания мер пресечения; расположением от менее строгих к более строгим; применением более строгой меры пресечения за нарушение избранной меры пресечения; возможностью изменения меры пресечения при изменении оснований для ее избрания и отмены меры пресечения, когда в ней отпадает необходимость.

В соответствии с ст. 98 УПК РФ, мерами пресечения являются: подписка о невыезде; личное поручительство; наблюдение командования воинской части; присмотр за несовершеннолетним обвиняемым; запрет определенных действий; залог; домашний арест; заключение под стражу.

Известны различные классификации мер пресечения. Так, Л.И. Фенин делил все меры пресечения в зависимости от вида обеспечения на две категории (группы): меры, имеющие своим содержанием личное и имущественное обеспечение[14]. При этом, домашний арест и задержание, т.е. лишение свободы до вынесения судебного приговора, он относил к мерам личного обеспечения.

Профессор М.А. Чельцов, все меры пресечения, предусмотренные УПК РСФСР 1923 г., в зависимости от вида оказываемого ими воздействия, подразделял на две категории:

1. меры пресечения психологически-принудительного характера;

2. меры пресечения физически-принудительного характера (лишающие обвиняемого свободы) [15].

По мнению В.А. Михайлова, система мер пресечения, как в целом, так и каждая из мер пресечения должны определяться характером, свойствами совершенных обвиняемым преступлений, видом и строгостью установленных за них санкций, тяжестью угрожающих уголовных наказаний[16]. При этом он подразделял меры пресечения, имеющие своим содержанием 1) личное обеспечение; 2) имущественное обеспечение; 3) морально-нравственное обеспечение и 4) административно-властное обеспечение. В четвертую группу автор включил заключение под стражу, домашний арест, наблюдение командования воинской части и присмотр за несовершеннолетним обвиняемым.

Ю.Г. Овчинников разделил меры пресечения на следующие группы:

1. оказывающие морально-личностное воздействие: подписка о невыезде, личное поручительство, присмотр за несовершеннолетним подозреваемым или обвиняемым родителями, опекунами, попечителями или другими заслуживающими доверия лицами;

2. оказывающие административно-властное воздействие: наблюдение командования воинской части, присмотр за несовершеннолетним подозреваемым или обвиняемым должностными лицами специализированного детского учреждения;

3. оказывающие имущественное воздействие: залог;

4. оказывающие физическое воздействие в виде ограничения личной свободы: запрет опреде- 
ленных действий, домашний арест и заключение под стражу[17].

Мера пресечения может быть избрана в отношении обвиняемого, а в исключительных случаях - в отношении подозреваемого. В данном случае обвинение должно быть предъявлено подозреваемому не позднее 10 суток с момента применения меры пресечения, а если подозреваемый был задержан, а затем заключен под стражу - в тот же срок с момента задержания. Если в этот срок обвинение не будет предъявлено, то мера пресечения немедленно отменяется, за исключением случаев, предусмотренных ч. 2 ст. 100 УПК РФ, при этом подозреваемому должно быть предъявлено обвинение в совершении хотя бы одного из преступлений, предусмотренных статьями 205, 205.1, 205.3, 205.4, 205.5, 206, $208,209,210,277,278,279,281,360$ и 361 УК РФ, не позднее 45 суток с момента применения меры пресечения.

В законе не указано, в чем может заключаться исключительность случаев избрания меры пресечения в отношении подозреваемого. Как полагает В.А. Светочев, исключительность должна выражаться в «весомом» подтверждении подозрения в совершенном преступлении. К примеру, при наличии соответствующей, хотя и первоначальной, но в то же время допустимой доказательственной базы или при наличии оснований для задержания лица в качестве подозреваемого[18].

Представляется, что исключительность случаев избрания меры пресечения в отношении подозреваемого, когда следователь не располагает достаточными доказательствами, дающими основание для обвинения в совершении преступления, связана с его повышенной общественной опасностью. При этом, в обоснование данной трактовки исключительности, можно указать установление законодателем срока в 45 суток для предъявления подозреваемому, которому избрана мера пресечения, обвинения в совершении хотя бы одного из преступлений, предусмотренных статьями 205, 205.1, 205.3, 205.4, 205.5, 206, 208, 209, 210, 277, 278, 279, 281, 360 и 361 УК РФ.

Меры пресечения, несмотря на их относительное разнообразие и неодинаковую степень использования принуждения, обладают несколькими общими отличительными признаками: они могут применяться только на основании специального мотивированного процессуального решения (постановления), которое вправе принять дознаватель, следователь или суд; меры пресечения могут применяться на длительный срок, в некоторых случаях ограниченный специальными периодами, исчисляемыми месяцами (с возможностью продления), а в других - вовсе не ограниченный ничем, кроме общих сроков производства по уголовному делу; меры пресечения по общему правилу применяются только к обвиняемому.

Меры пресечения в российском уголовном судопроизводстве имеют общие основания для избрания, изменения, отмены и прекращения.

Правильное избрание и применение мер пресечения полностью зависит от осознания субъектами правоприменения цели, оснований и условий для их применения.

Слово «основание» означает «существенную часть, отношение, порождающую какого-нибудь явление, разумная причина, повод...» [19].

В соответствии с ч. 1 ст. 97 УПК РФ, дознаватель, следователь, а также суд в пределах предоставленных им полномочий вправе избрать обвиняемому, подозреваемому одну из мер пресечения, предусмотренных УПК РФ, при наличии достаточных оснований полагать, что обвиняемый, подозреваемый: скроется от дознания, предварительного следствия или суда; может продолжать заниматься преступной деятельностью; может угрожать свидетелю, иным участникам уголовного судопроизводства, уничтожить доказательства либо иным путем воспрепятствовать производству по уголовному делу.

Избрание любой меры пресечения при наличии предусмотренных законом оснований, возможно только при определенных условиях. Слово «условие» означает «то, что делает возможным что-нибудь другое, что определяет собою что-нибудь другое» [19].

Н.В. Буланова к условиям избрания меры пресечения относит обстоятельства, создающие правовую ситуацию, которая допускает возможность применения меры пресечения. Такими условиями выступают наличие возбужденного уголовного дела и привлечение лица в качестве подозреваемого или обвиняемого[20].

В.А. Светочев считает, что под условиями избрания меры пресечения в виде домашнего ареста следует понимать совокупность уголовно-процессуальных и фактических обстоятельств, позволяющих избрать данную меру пресечения и обеспечить законность такого избрания[18].

Разделяя мнение указанных авторов, отметим, что под условиями следует понимать установленные уголовно-процессуальным законом обстоятельства, позволяющие избрать меру пресечения при наличии оснований.

При этом основное отличие условий от оснований избрания меры пресечения состоит в том, что к условиям 
относятся процессуальные, правовые обстоятельства, такие как наличие возбужденного уголовного дела, привлечение лица в качестве обвиняемого и т.д., а к основаниям относятся содержащиеся в материалах уголовного дела сведения, позволяющие сделать вывод о том, что подозреваемый, обвиняемый может совершить действия, указанные в ч. 1 ст. 97 УПК РФ.

При решении вопроса об избрании в отношении подозреваемого или обвиняемого определенной меры пресечения необходимо наличие совокупности общих и специальных (предусмотренных уголовно-процессуальным законом для данной меры пресечения) условий, отсутствие одного из них должно повлечь невозможность избрания данной меры пресечения.
Для избрания меры пресечения необходимо наличие указанных в законе оснований, общих и специальных условий, соблюдение которых обеспечивает реализацию принципа законности, защиту прав подозреваемого, обвиняемого при избрании данной меры пресечения.

Таким образом, меры пресечения - это меры уголовно-процессуального принуждения, избираемые субъектом расследования или судом в отношении обвиняемого или подозреваемого при наличии оснований, предусмотренных уголовно-процессуальным законом, в целях обеспечить участие в производстве по уголовному делу, а также для создания условий надлежащего производства по уголовному делу, и заключающиеся во временном ограничении их прав и свобод.

\section{ЛИТЕРАТУРА}

1. Белоусов А. Е. Вопросы теории и практики применения мер уголовно-процессуального пресечения по законодательству Российской Федерации: автореф. дисс. ... кад. юрид. наук. Ижевск, 1995. 25 с.

2. Коврига 3. Ф. Уголовно-процессуальное принуждение. Воронеж, 1975. 174 с.

3. Кондрат И.Н. Обеспечение прав личности в досудебном производстве по уголовным делам: законодательное регулирование и правоприменительная практика: монография. М. Юстицинформ, 2015. 176 с.

4. Григорьева А. Е. Вопросы теории и практики избрания следователями органов внутренних дел отдельных мер пресечения: залога и домашнего ареста: автореф. дис. ... канд. юрид. наук. Красноярск, 2009. 22 с.

5. Петрухин И.Л. // Уголовно-процессуальное право Российской Федерации: учебник. 3-е изд. перераб. и доп. / Отв. ред. И. Л. Петрухин, И. Б. Михайловская. М. Проспект, 2014. 685 c.

6. Давыдов П. М. Меры пресечения в советском уголовном процессе: автореферат дис. ... канд. юрид. наук. Л., 1953. 15 с.

7. Ожегов С.И., Шведова Н. Ю. Толковый словарь русского языка. М.: «АЗъ», 1993. 907 с.

8. Строгович М. С. Уголовный процесс: Учебник для юридических вузов. М. Изд. НКЮ СССР, 1940. 311 с.

9. Лившиц Ю. Д. Меры процессуального принуждения в советском уголовном процессе: автореф. дис. ... канд. юрид. наук. М., 1958. 18 с.

10. Коврига 3. Ф. Указ. соч. С. 84; Лившиц Ю. Д. Указ. соч. С. 5-6; Михайлов А. В. Меры пресечения в российском уголовном процессе. М. Право и Закон, 1996. $269 \mathrm{c}$.

11. Ивлев Г.П. Основания и цели применения мер процессуального принуждения // Государство и право. 1995. № 11. С. 77.

12. Еникеев 3. Д. Проблемы мер пресечения в уголовном процессе: автореф. дис. ... д-ра юрид. наук. Екатеринбург, 1991. 42.

13. Ткачева Н. В. Мера пресечения - домашний арест // доклады и сообщения на учредительной конференции Международной ассоциации содействия правосудию. Санкт-Петербург, 5-6 октября 2005 / Под ред. А. В. Смирнова, Спб., 2005. с. 74-77.

14. Фенин Л. И. Уголовный процесс. Харьков, 1911.179 с.

15. Чельцов М. А. Уголовный процесс. М., 1948. 624 с.

16. Михайлов В. А. Комментарий к Уголовно-процессуальному кодексу Российской Федерации / Под общ. ред. В. В. Мозякова. М. Экзамен XXI, 2002.1280 с.

17. Овчинников Ю. Г. Домашний арест как мера пресечения в уголовном процессе: дис. ... канд. юрид. наук. Омск, 2006. 206 с.

18. Светочев В. А. Домашний арест как мера пресечения в уголовном процессе Российской Федерации: дис. ... канд. юрид. наук. Калининград, 2009. 213 с.

19. Ушаков Д. Н. Толковый словарь русского языка. М. Альта-Принт, 2005. 1216 с.

20. Буланова Н. В. Заключение под стражу при предварительном расследовании преступлений: Научно-методическое пособие / Под ред. докт. юрид. наук М. Е. Токаревой. М. Изд-во «Юрлитинформ», 2005. 256 с.

21. Буланова Н. В. Заключение под стражу при предварительном расследовании преступлений: Научно-методическое пособие / Под ред. докт. юрид. наук М. Е. Токаревой. М. Изд-во «Юрлитинформ», 2005. 256 с. 